\begin{tabular}{|c|c|c|}
\hline 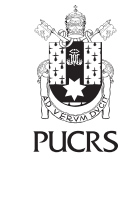 & $\begin{array}{l}\text { ESCOLA DE } \\
\text { HUMANIDADES }\end{array}$ & $\begin{array}{l}\text { Revista de Filosofia da PUCRS } \\
\text { Veritas, Porto Alegre, v. 65, n. 1, p. 1-12, jan.-mar. } 2020 \\
\text { e-ISSN: 1984-6746 | ISSN-L: 0042-3955 }\end{array}$ \\
\hline def $h t \mathrm{tp}: / / \mathrm{dx}$. & $.0 \mathrm{rg} / 10.15448 / 1984-6746.2020 .1 .36862$ & \\
\hline
\end{tabular}

SEÇÃO: MORAL \& POLITICAL PHILOSOPHY

\title{
O problema da fundamentação da moral e a ética feminista
}

\author{
The problem of moral justification and feminist ethics \\ El problema de la fundamentación de la moral y la ética feminista
}

\section{Viviane Magalhães \\ Pereira $^{1}$}

orcid.org/0000-0002-7821-5103

viviane.pereira@uece.br

Recebido em: 15 jan. 2020.

Aprovado em: 30 jan. 2020

Publicado em: 12 mai. 2020.
Resumo: Este artigo tem como tema o problema filosófico da fundamentação da moral com o objetivo de apresentar o sentido e a validade de uma ética feminista. Parte-se da hipótese de que uma ética feminista se distinguiria das éticas antigas e apresentaria uma alternativa adequada ao problema da fundamentação da moral, bem como dos conflitos morais atuais, em especial, pelo tipo de solução que propõe, a qual segue uma lógica construida mediante uma práxis humana determinada. Em outros termos, o objetivo deste artigo é ajudar a compreender como um conteúdo da moralidade surgido de elementos históricos, temporais, culturais pode ser construido; nesse caso, ligado às condições das mulheres surgidas no meio social. Para tanto, será apresentada uma nova concepção de ética e o exemplo de uma ética capaz de orientar uma solução para conflitos morais atuais, a ética feminista do cuidado de Carol Gilligan.

Palavras-chave: Fundamentação da moral. Éticas antigas. Ética feminista. Ética do cuidado.

Abstract: This paper focuses on the philosophical problem of moral justification with the aim of presenting the sense and validity of a feminist ethics. It is assumed that a feminist ethics would differ from the ancient ethics and would present an adequate alternative to the problem of moral justification as well of the current moral conflicts. It proposes a solution which follows a logic built by a determined human praxis. In other words, the aim of this paper is to help understand how a content of morality resulted from historical, temporal e cultural elements can be constructed. Such elements in this case are related to the women's conditions arising in the social environment. But that requires that a new conception of ethics be presented to guide a solution to current moral conflicts as the Carol Gilligan's feminist ethics of care.

Keywords: Moral justification. Ancient ethics. Feminist ethics. Ethics of care.

Resumen: Este artículo tiene como tema el problema filosófico de la fundamentación de la moral con el objetivo de presentar el sentido y la validez de una ética feminista. Se parte de la hipótesis de que una ética feminista se distinguiría de las éticas antiguas y presentaría una alternativa adecuada al problema de la fundamentación de la moral y de los conflictos morales actuales, en particular por el tipo de solución que propone, la cual sigue una lógica construida mediante una praxis humana determinada. En otros términos, el objetivo de este artículo es ayudar a comprender cómo un contenido de la moralidad surgido de elementos históricos, temporales, culturales puede ser construido; en este caso vinculado a las condiciones de las mujeres surgidas en el medio social. Para ello, se presentará una nueva concepción de ética y el ejemplo de una ética capaz de orientar una solución a conflictos morales actuales, la ética feminista del cuidado de Carol Gilligan.

Palabras clave: Fundamentación de la moral. Éticas antiguas. Ética feminista. Ética del cuidado. 


\section{Introdução}

Há uma passagem instigante do texto "Um teto todo seu" de Virginia Woolf, em torno do qual se anuncia a problemática de uma ética feminista.

A vida [...] é árdua, difícil, uma luta perpétua. Requer coragem e força gigantescas. Mais que qualquer coisa, talvez, criaturas da ilusão como somos, ela requer confiança em si mesmo. Sem autoconfiança, somos como bebês no berço. E de que modo podemos adquirir essa qualidade imponderável, que também é tão inestimável, o mais rápido possivel? Pensando que as outras pessoas são inferiores. Sentindo que temos uma superioridade inata - pode ser riqueza, status, um nariz perfeito l...]; os artifícios da imaginação humana não têm fim - sobre os outros. Por isso a enorme importância para o patriarcado de ter de conquistar, ter de governar, de achar que um grande número de pessoas, metade da raça humana, na verdade, é por natureza inferior (WOOLF, 2014, p. 53-54).

Concordamos com Woolf de que a vida para todas as pessoas seja dificil, porque ela não possui um único aspecto. Como muito bem destaca a filósofa Martha Nussbaum em uma entrevista, a vida para todas as pessoas já pode ser dita "uma luta", porque as pessoas querem ser saudáveis, querem oportunidades de emprego, querem educação, liberdade política e religiosa, querem manter boas relações com outras pessoas, tanto no espaço de trabalho como fora dele. Querem um acesso significativo à natureza. Querem, esperamos, um meio ambiente sem poluição. E elas também querem controlar propriedades materiais, eàs vezes um pedaço de terra. Elas não querem que os grandes proprietários controlem suas terras. Mas, apesar de todas quererem ao mesmo tempo algumas dessas oportunidades, apenas algumas poucas entre elas podem sempre escolher entre oportunidades (FRONTEIRAS DO PENSAMENTO, 2018).

Contudo, talvez a vida seja sempre árdua para todas as pessoas, porque, mais que qualquer coisa, ela requeira confiança em si mesmo. Sem autoconfiança somos vulneráveis e, portanto, dependentes, condições que, de um ponto de vista existencial, representam uma perda de "nossa humanidade", isto é, de nossa capacidade de pensar e imaginar, que torna nossas relações ricas, em vez de relações meramente utilitárias e manipuladoras (NUSSBAUM, 2015, p. 7). Considerando que autoconfiança seja um aspecto fundamental de nossa existência, ela seria a condição de, em sociedades humanas gestadas pela necessidade de sentido, crermos em nossa integridade, termos amor por nós mesmos/as, justificarmos o que fazemos e como fazemos, tudo isso tendo em vista a duração de nossa vida, como se seu todo possuísse um sentido superior e, assim, estarmos aptos/as a suportar a ela e a nós mesmos.

Adotando a hipótese da existência desse fenômeno humano comum, logo nos deparamos com a seguinte aporia: de que modo podemos adquirir essa qualidade que não podemos medir, se há diversos modos de ser e viver, e a princípio não há nada que racionalmente distinga o modo como sou e vivo, como se fosse um modo bom/ melhor/superior, ou ainda, se o outro pleiteia o mesmo direito de o seu modo de ser e viver ser o melhor, de tal modo que isso resulte em conflitos? Woolf indica que existe um modo rápido de fazê-lo: "Pensando que as outras pessoas são inferiores. Sentindo que temos uma superioridade inata" (WOOLF, 2014, p. 53). Em outros termos, esse é um modo rápido de proceder, que identificamos tanto no modo de ser de certos individuos, em certas organizações sociais, como em certas concepções de moral (morais antigas), que têm a pretensão de resolver aquela aporia. Nesse caso, os conflitos reais poderiam ser resolvidos, se aquele/s que se julga/m superior/es conquistar/em, dominar/ em aqueles que são inferiores.

Woolf cita o exemplo do patriarcado, da forma de organização social em que predomina a autoridade paterna, masculina (um papel que também pode ser desempenhado por mulheres), que busca conquistar, governar e "achar que um grande número de pessoas, metade da raça humana, na verdade, é por natureza inferior" (WOOLF, 2014, p. 53-54). Levantamos aqui outra hipótese, ampliando essa discussão, que o patriarcado se fortalece, em relação a esse aspecto destacado, na medida em que atua junto às normas de diversas concepções de moral vigentes historicamente nas mais diversas 
sociedades humanas. Essa "parceria" seria um modo muito mais eficaz de alcançar aquela "solução rápida", do que práticas isoladas de determinados individuos, justamente porque internalizamos uma moral por meio da familia, da cultura, da educação, pelo simples fato de fazermos parte de alguma sociedade muito antes de sermos capazes de julgar criticamente aquele aspecto da existência humana e o alcance e valor das soluções disponíveis, para ao menos lidar, se chegarmos à conclusão de que não é possivel resolver, com o problema da convivência entre os diferentes.

\section{A tarefa da ética de fundamentação da moral e os limites das éticas antigas}

Antes de explicar qual a diferença entre adotar uma "solução rápida" e avaliar "soluções disponiveis", como possibilidades concretas, vale destacar que o fato de uma organização social ter que estruturar as partes conflitantes da sociedade não significa nem que organizações sociais devam ter como princípio considerar que parte da raça humana seja inferior (mulheres, mas também negros/as, judeus/ias, pobres etc.), isto é, de que somente possam se estabelecer dessa maneira, nem que elas devam fundar uma moral ou ser fundadas com base em uma moral. De modo análogo, o fato de uma moral ser um sistema composto por normas/regras/juizos morais de que certo agir seja bom ou mau, e de que, com base nisso, algo deva ser permitido ou proibido, propondo, portanto, ações concretas em casos concretos, não significa que concepções de moral devam sempre excluir com regras determinadas maneiras de ser e viver, como se representassem um obstáculo para o bem comum e, portanto, devessem ser "interditadas", impedidas de ser exatamente como são.

Que haja organizações sociais e concepções de moral que se entrecruzam significa, antes de tudo, apenas que seres humanos adotam leis e valores, que, uma vez seguidos, solucionariam/ atenuariam problemas concretos, especialmente, aqueles problemas diante dos quais nos sentimos desorientados/as e por razões de humanidade. são entendidos como urgentes. Esse é o caso dos problemas globais da sujeição, isto é, da condição de muitas mulheres, trabalhos análogos à escravidão etc., mas também do aborto, da pobreza no mundo, das próximas gerações, da imigração etc. Nesses casos, os juízos morais assumem um papel importante (Nunca sujeite/ escravize alguém! Não destrua o meio ambiente!) e sem eles deixaria de existir a possibilidade de repreensão e de fazer censuras e, com isso, provavelmente nos relacionariamos uns com os outros apenas instrumentalmente, ou mesmo deixariamos de ser humanos/as, na medida em que as disputas no âmbito da moral se decidiriam de maneira definitiva (TUGENDHAT, 2012, p. 21-22).

A moral é considerada, portanto, parte de nossa humanidade, porque leis e valores podem ser questionados quanto à eficácia na solução/ atenuação de problemas morais concretos, de tal modo que outros sistemas de normas podem surgir com pretensão de surtirem melhores efeitos, quando já inclusive provaram surtir melhores resultados em outros contextos. Em outras palavras, saberes normativos não precisam servir de referência para toda nossa vida, mas unicamente para a obtenção de certos resultados que supostamente buscamos (CORTINA, 2015. p. 11) enquanto humanidade, e devem levar em consideração a combinação de nossas possibilidades de atuação com o contexto, ou seja, com a realidade concreta constituída pela interação de múltiplos aspectos, e não apenas por aqueles que convenientemente podemos querer destacar.

Na história da humanidade encontramos o exemplo de reformadores/as e morais reformadoras que trouxeram propostas de uma nova moral em sua época e apresentaram boas razões para se segui-la. Seria absurdo pensar hoje, especialmente quando nos vemos perdidos diante de tantos conflitos morais, que leis e valores não devam continuar em aberto, acreditando que eles surgem espontaneamente da natureza, da sociedade, de uma razão pura etc. Isso seria o mesmo que descaracterizar e desconsiderar os atributos humanos, os quais são fundamentalmente diferentes, e acobertar 
os interesses particulares e/ou coletivos que estão por detrás da tentativa de manter, muitas vezes a todo custo, uma concepção moral antiga ou vigente e, com ela, a dita "superioridade inata" de determinadas maneiras de ser e viver.

Essa reflexão sobre as diferentes morais é uma das tarefas da ética filosófica, mas não a única. Talvez a sua tarefa fundamental seja apresentar as diferentes maneiras de justificar racionalmente a moral e, com isso, eleger algum principio ético fundamental justificado racionalmente que pretenda orientar melhor as ações dos seres humanos. Isso significa que a ética é também um saber normativo, mas diferentemente das diversas concepções de moral, ela pretende orientar aquelas ações apenas indiretamente (CORTINA, 2015, p. 9), isto é, com um princípio fundamental, que expressa de maneira racional apenas uma ideia de bem universal, e não normas morais. Esse modo racional de proceder da ética filosófica faz com que ela não seja uma "solução simples" para o problema do que consideramos ser melhor fazer, e de como podemos da melhor maneira nos compreender ante o que fazemos, porque não só precisa justificar racionalmente o que propõe, como põe apenas alguns limites, embora fundamentais, para problemas reais, cabendo ainda a nós decidir a cada vez, ante cada situação, o que é melhor fazer aqui e agora.

Seria, no entanto, menos complicado se pudéssemos justificar racionalmente a vida moral mesmo que parcialmente de maneira absoluta. Isso significa que se não for possivel determinar de maneira definitiva ações concretas para casos concretos, talvez possamos, ao menos, determinar de maneira definitiva princípios, isto é, orientações indiretas e gerais para as ações humanas, para acabarmos, pelo menos em parte, com as disputas no âmbito da moral. A primeira pergunta que podemos fazer em relação a essa tentativa é em que medida ela se distinguiria da fundamentação religiosa de princípios, e a resposta é, que em relação à fundamentação, não se distinguiria.

Sabemos (ou deveríamos saber) que o problema de uma fundamentação religiosa da moral é que a justificação de seu princípio (baseado no conceito de Deus, na ideia de perfeição, conforme apresentados nos textos sagrados), supõe que seja simples derivar dai suas normas e que todos/as nós sejamos/tenhamos que ser crentes, quando, ao mesmo tempo, não há ética conciliatória, isto é não podemos "fazer alguém aceitar [principios,] recomendações, sugestões, conselhos ou até instruções, que ele mesmo não veja ou reconheça" (GADAMER, 2000, p. 40). Além disso,

[...] seria intelectualmente desonesto
manter-se ligado a respostas religio-
sas para as questões morais, apenas
porque elas permitem soluções sim-
ples, o que não corresponderia nem
à seriedade das questões, nem à se-
riedade exigida pela crença religiosa.
Entretanto, também o crente não pode
mais fundar suas normas morais em
sua crença religiosa, pelo menos se
ele leva a sério o não crente e aque-
le que possui uma crença diferente
da sua. Pois a observância de normas
morais é algo que podemos exigir de
todos (de qualquer forma, assim parece
ser), e, para podermos fazê-lo, deve-
mos também esperar que isso possa
ser tornado compreensivel para todos
(TUGENDHAT, 2012, p. 13).

Já uma fundamentação racional da moral propõe uma ética que seja acessivel a todos os seres humanos, mas é um problema em ética saber como uma moral se deixa fundamentar racionalmente em um principio. Um pensador que tentou solucionar esse problema filosófico foi Immanuel Kant (1724-1804), mas falhou por afirmar que o principio fundamental da moralidade era apenas aquele do imperativo categórico (Age diante de todos de tal modo que tu irias querer. a partir da perspectiva de qualquer pessoa, que os outros agissem!), e que isso se provaria por meio de um "fato da razão" pura humana (liberta dos afetos, exceto do sentimento de respeito), na qual se construiria autonomamente essa lei, bem como as demais leis práticas, as quais legislam sobre outros aspectos essenciais da práxis humana - direito, política, educação (LOPARIC, 2003. p. 2-3). Para ele, negar tais leis seria o mesmo que entrar em contradição consigo mesmo, com a razão pura que todos os seres humanos partilham, o que seria um 
empecilho para quem está buscando aquela tão imponderável autoconfiança.

Embora haja interpretações variadas em relação a essa questão, entendo que a fundamentação kantiana da moral está baseada nesse "fato da razão" (KANT, 2002, p. 37), que "não prova que o imperativo categórico é condição necessária da moralidade dos juizos e das ações" (LOPARIC, 1999, p. 34), embora possamos considerar o imperativo categórico do ponto de vista do conteúdo (TUGENDHAT, 2012, p. 80-81) um bom candidato para a orientação de juizos e ações morais, que solucionariam conflitos morais. 0 problema de uma fundamentação kantiana é que. apesar de se dizer puramente racional, ela supõe. de modo similar à fundamentação religiosa, como o próprio Kant afirma em diversas passagens de seus textos sobre ética, que seres humanos saberiam facilmente distinguir o que é bom e o que é mau, e o que é conforme ao princípio moral ou que é contrário a ele, pelo simples fato de terem uma faculdade da razão (KANT, 2011, p. 37), e que nós julgariamos moralmente como membros de uma espécie de comunidade universal virtual na qual os seres humanos estariam ligados pela razão.

$\mathrm{Na}$ verdade, com isso, ele conseguiu apenas provar que existe um querer racional moral que pode querer determinada forma de julgar, mas dizer com ele que todo querer para ser racional deve querer essa forma determinada de julgar significa construir uma moral inconsciente da gênese sociopsicológica de seus ideais, não sendo capaz de compreender, por exemplo. por que razão muitas ações defendidas como morais produzem consequências profundamente contraditórias, imprevistas ou mesmo imorais (SAFATLE, 2013, p. 10, 12, 16). Isso significa que ele conseguiu provar que é possivel fundar a moral racionalmente, com o seu programa do imperativo categórico, mas não que ele fosse o único que pode se apresentar como racional (também o utilitarismo e a ética do cuidado o fazem).

O problema desse tipo de fundamentação foi, portanto, ter entendido a obrigação moral (o que eu me vejo obrigada a fazer, porque é bom e, portanto, dá sentido à minha existência) sem reciprocidade, supondo que a escolha moral pelo que possua um sentido bom tenha um sentido absoluto ou consista puramente em racionalidade (TUGENDHAT, 2003, p. 15), como se para ele, não julgássemos apenas como membros de uma comunidade (internalizando hábitos, crenças e autoridades presentes nos costumes ligados pela tradição) e como se os afetos não tivessem uma conexão fundamental com juizos morais, podendo estes ser puros.

Julgamos necessário apresentar dois tipos de fundamentação dogmáticos da moral para destacar duas questões sobre as quais queremos a partir de agora refletir: 1) nenhuma dessas fundamentações resolveu racionalmente o problema da fundamentação da moral de maneira satisfatória; 2) nenhuma delas é neutra, pois ambas terminam privilegiando determinada forma de julgar (do crente; de um ser que busca se apartar das relações e dos afetos); e 3) nenhuma delas apresentou suficientemente uma solução para certos problemas morais urgentes (a condição de sujeição das mulheres, dos escravos etc.), não contribuindo ou dificultando mais ainda que muitas pessoas pudessem desenvolver aquela confiança em si mesmas e, inclusive, contribuir para uma concepção de organização social e uma concepção de moral mais amplas e mais justas.

Além disso, uma fundamentação absoluta combinada com preconceitos de uma época termina dando razões, embora injustificadas, para que muitos aceitem (tenham aceitado) como válidos juízos e ações que representam um obstáculo/ameaça para a realização de muitas pessoas e sua participação na organização da sociedade. Esse é o caso da fundamentação moral kantiana que combinada ao preconceito de Kant de que as mulheres seriam incapazes de pensar por si mesmas, de se desligar do caos dos afetos, "porque [...] todo o belo sexo [...] considera a passagem à maioridade dificil e também perigosa", faz com que seja possivel aceitar "que os tutores de boa vontade [tomem] a seu cargo a superintendência" (KANT, 2016, p. 10) das mulheres. 


\section{A proposta de uma nova fundamentação da moral e o exemplo da ética feminista}

O conceito de moral que defendemos aqui e. com ele, a possibilidade de uma ética filosófica hoje, é definido em termos por Ernst Tugendhat e se aproxima do modo como a palavra moral é definida na etnologia (no caso da moral, estudo do fato da moral, buscando uma apreciação analítica e comparativa das culturas): ela "consiste naquelas regularidades do comportamento que se baseiam na pressão social" (TUGENDHAT, 2003. p. 15). Em outras palavras, a moral (e também a ética) é normativa, porém suas normas podem mudar segundo pressões sociais. Contudo, esse modo de pensar é objeto de algumas acusações equivocadas e superficiais, como conservadorismo moral, empirismo ou naturalismo e sociologismo combinados (ROCHA, 2007, p. 123-124), quando, vale destacar, se assim o fosse, nem se poderia justificar, uma vez que esses modelos não se podem sustentar por uma argumentação racional, o que é uma exigência da filosofia.

O modelo de conservadorismo moral é uma ideologia original que toma como base única para a moral as raizes morais históricas de uma sociedade e as tradições e instituições morais herdadas, que é avesso a mudanças em moral. Um exemplo de juizo moral conservador é: a tradição religiosa baseada nas sagradas escrituras mostra que uma mulher ser submissa (dependente e obediente) a um homem (no caso o marido) é algo bom, porque é assim que todos/as deveriam proceder, agradando e não reagindo, e a mulher é justamente o ser que está destinado [por Deus] a ter de dar esse exemplo de perfeição (BíBLIA, 2018, p. 495, I PEDRO, 3, 1-7). Esse seria um juizo moral conservador porque reproduz um julgamento moral antigo, baseado na crença do valor absoluto (independentemente das mudanças de comportamentos, hábitos, crenças, autoridades) de uma norma presente em um texto sagrado e do principio em que se funda, com pretensão de valer para todos os seres humanos (mesmo os não crentes), mesmo que esse juizo tenha produzido (produza) consequências profundamente contraditórias, imprevistas ou mesmo imorais (contraditória: mulheres terem a oportunidade de desempenhar somente ou especialmente aqueles papeis sociais "tradicionais" - ser mãe/uma mãe amorosa, agradar o marido -, quando muitas vezes se sentem limitadas, infelizes e alienadas nesses papeis (BADINTER, 2011; DONATH, 2017); imprevista: mulheres não serem consideradas como sujeitos de interesses e direitos e, portanto, terem que sofrer todos os "excessos" dos homens, mesmo as ações violentas, sem reagir/resistir; imoral: homens terem privilégios (BEAUVOIR, 2016), não serem responsabilizados por porem mulheres em condição de sujeição, abandono, violência etc.).

A crença em tradições e instituições morais jamais nos mostrará que sujeitar mulheres, ou seja, tornar mulheres seres dependentes e obedientes é algo bom ou ruim, ou mesmo será suficiente para evitar que se produza nesse modelo aquelas consequências profundamente contraditórias, imprevistas ou mesmo imorais. Uma ideologia original de apego às raizes morais históricas de uma sociedade somente pode fundamentar um juízo que diz que mulheres e homens crentes, a este ou aquele texto sagrado, deste ou daquele circulo cultural ou religioso, acreditam (ou acreditaram) em um tal tipo de ação como boa ou aceitável.

Já o modelo empirista em moral é uma doutrina segundo a qual uma concepção de moral pode surgir com base unicamente no conhecimento que provém da experiência e que se forma na sensibilidade cognitiva (ligada aos sentidos), sendo geralmente descartadas, por exemplo, as verdades que tiveram a participação de alguma construção racional pura. Um exemplo de juízo moral empírico é: com base no que a experiência mostra, uma mulher ser subjugada e agradar o homem é algo bom, porque, como se pode verificar observando seus comportamentos, isso é o melhor que ela consegue fazer, essa é a maneira de ela contribuir para o progresso humano (ROUSSEAU, 2004, p. 516-517). Esse seria um juizo moral empírico, porque é construido com base em uma descrição de comportamentos praticados e/ou aceitos, segundo o qual se defende que é plausivel em moral tomar o efeito pela causa. Em outros termos, é como defender que é porque algo acontece de um modo, que está fundamentalmente 
destinado/determinado a acontecer desse modo, um absurdo que é contestado tanto do ponto de vista racional (WOLLSTONECRAFT, 2016, p. 62), como pela própria história.

Esse modo de pensar também produziu (produz) consequências tão profundamente contraditórias, imprevistas ou mesmo imorais, como aquele modelo de conservadorismo moral. Além disso, a experiência jamais nos mostrará que tornar mulheres seres dependentes e obedientes é algo bom ou mesmo ruim. A única coisa que podemos fundamentar empiricamente é um juízo que diz que mulheres e homens deste ou daquele círculo cultural, desta ou daquela classe social consideram e adotam (ou consideraram e adotaram) um tal tipo de ação como boa ou aceitável. O curioso, ao se pensar com a ética filosófica, é não apenas observar que diferentes maneiras de justificar a moral são problemáticas, mas que muitas das acusações feitas às éticas não absolutas, como à ética feminista, são praticadas pelos próprios acusadores, como defensores autoritários e inflexiveis de morais antigas.

Contra a acusação de que uma moral e uma ética que podem mudar segundo pressões sociais incorre em naturalismo e sociologismo combinados, nos limitamos a dizer que defender que sociedades humanas somente possam sobreviver em um sistema de obrigações reciprocas, diferentemente de equiparar a situação dos seres humanos com a de outras espécies, onde o comportamento altruista é determinado geneticamente e funciona por instinto, significa apenas que a única determinação que é natural no ser humano e, portanto, está presente em todas as sociedades humanas, é a sua capacidade de aprender e construir normas. Essa capacidade nos deixa, no entanto, em uma situação em aberto, o que significa maior liberdade e flexibilidade, pois os sistemas de normas possuem uma estrutura que não se deixa explicar pelo modo como as sociedades estão organizadas e funcionam, uma vez que pode mudar historicamente segundo diversas condições surgidas no meio social (TUGENDHAT, 2003, p. 15), que geram uma pressão. Em contrapartida, essa situação em aberto significa também maior dificuldade e complexidade, o que ao invés de ser considerado um impedimento, pode indicar, na verdade, uma solução para lidarmos com os problemas morais atuais.

A situação das mulheres, sua condição de caráter social, econômico, profissional (serem estimuladas à ignorância, serem proibidas de/ enfrentarem dificuldades para ter acesso à educação formal, ter propriedade ou exercer certas profissões) é o exemplo que queremos enfatizar, pois gerou uma reflexão crítica e problematizante sobre a moral e a ética. Essa situação foi denunciada ao longo de séculos por mulheres e homens e, em especial, pelo feminismo. Esse conceito começa a ser usado em finais do século XIX, embora possamos falar em um "arqueofemismo" já presente nos séculos XVII e XVIII (ROVERE, 2019), e não é facilmente definivel nem tem fronteiras fixas. Vale dizer que esse conceito, assim como o conceito de filosofia, suporta flutuações e modificações pois pertence à categoria de conceitos que se consolidam em uma constante e progressiva construção/ formação. Isso significa que ele inclui múltiplas orientações, mas, antes de tudo, que ele também possui delineamentos comuns que o identificam, não podendo ser modificados conforme a preferência de seus opositores.

É comum a todo feminismo suas manifestações tanto na reflexão (filosofias) quanto na ação (movimentos sociais e políticos) e a presença indispensável da componente da práxis, isto é, o ter de posicionar-se tendo em vista sempre um estudo do contexto em sua complexidade, ou melhor, das diversas condições surgidas no meio social em interação. Já na origem do feminismo está a aspiração ética e a política da luta pela igualdade de direitos entre homens e mulheres, tendo em vista os papeis que as mulheres tinham que desempenhar na sociedade, bem como sua situação em geral. Essa aspiração feminista terminou inevitavelmente explorando campos que habitualmente pertencem à filosofia, "com especial incidência em temática ontológicas, antropológicas e éticas" (FERREIRA, 2009, p. 13-14).

No caso da ética, há diversas condições 
femininas surgidas no meio social que, assim como as condições de caráter social, econômico, profissional das mulheres, foram expostas tanto pelo feminismo, como por diversas filósofas, escritoras e cientistas (psicólogas, sociólogas), e contrariaram juizos de concepções morais que se fundam em dogmatismo, conservadorismo ou empirismo. Foi especialmente a exposição da condição feminina como resistência ou reinvenção, que ajudou a completar a tarefa de pensar uma ética filosófica hoje. São exemplos de resistência, seja decorrente de uma decisão ou não, estar mais suscetivel em determinados contextos ao mau desempenho de certos papeis, à depressão, à escolha de não ter filhos ou de não casar para não correr o risco de sofrer certas consequências, à exposição ao aborto, a resistir de maneira violenta, a ter de fazer greve, protestar etc. São exemplos de reinvenção buscar o autodidatismo, produzir obras geniais em situações adversas, como foi o caso de Jane Austen (WOOLF, 2014, p. 98), escolher não ter filho ou não casar por ter outras prioridades, desenvolver certas atitudes (participação, solidariedade, atenção ao outro, tolerância) e capacidades (imaginar a condição do outro), formar certos afetos (amor responsável, respeito pelo outro) etc.

Um estudo dessas condições, que geraram uma pressão, a qual contribuiu para a construção de uma nova fundamentação da moral, foi realizado na área de psicologia social de maneira inovadora pela filósofa e psicóloga feminista Carol Gilligan (1936-), e ganhou repercussão mundial em 1982 com a publicação de seu livro Uma voz diferente. Antes de tudo, não passa despercebido que temos ai uma mulher como sujeito de pesquisa, mas também vale destacar que em sua pesquisa as mulheres foram incluidas como objetos de pesquisa e se utilizou um método que buscou dar voz às pessoas, partindo da hipótese de que mais importante do que o enfoque que se pode dar à pesquisa, "o modo como as pessoas falam de suas vidas é significativo; a linguagem que utilizam e as conexões que fazem revelam o mundo que elas veem e no qual atuam" (GILLIGAN, 1982, p. 12).
Esse método foi construído após cinco anos de uma de suas investigações, que era sobre identidade e desenvolvimento do raciocinio moral, quando 1) ela começou a ouvir "dois modos diferentes de falar sobre problemas morais", sobre julgamento e ação em uma situação de conflito e escolhas morais entre opções, "dois modos de relatar o relacionamento entre o outro e o eu", e 2) começou "a observar problemas recorrentes ao interpretar o desenvolvimento das mulheres e associar esses problemas com a reiterada exclusão das mulheres dos estudos teorizantes críticos da pesquisa psicológica". Um problema como esse é considerar que "a disparidade entre a experiência das mulheres e a representação do desenvolvimento humano", a qual apareceria até a época de Gilligan em toda a bibliografia psicológica, deveria significar que há um problema no desenvolvimento das mulheres. Para a filósofa, em vez disso, "o fato de que as mulheres não se ajustem aos modelos existentes de crescimento humano pode lindicar. na verdade,l um problema na representação, uma limitação na concepção da condição humana, uma omissão de certas verdades sobre a vida" (GILLIGAN, 1982, p. 11).

O mais relevante nesse estudo de certas condições femininas, que levou à construção de seu método e pôde contribuir para modificar a moral e a ética, não foi, portanto, o fato de elas terem surgido de uma observação empirica das mulheres, mas a compreensão mais ampla e mais justa que se pôde conquistar. ao passo que se revelaram essas condições. Uma compreensão desse tipo em relação à condição humana, que seria a compreensão de uma voz diferente, teve que considerar que uma voz, embora esteja/possa estar associada às mulheres, não se caracteriza pelo gênero, mas por um modo diferente de pensar. Ao tomar isso como base e passar a considerar a interação de experiência e pensamento, as vozes diferentes e os diálogos que elas suscitam, o modo como ouvimos a nós mesmos e a outros, as histórias que contamos sobre nossas vidas (GILLIGAN, 1982, p. 12), Gilligan pôde superar o preconceito 
observacional e valorativo presente em teorias antigamente consideradas neutras/imparciais, que transmitiam para as mulheres, "por um lado, um ideal de ser humano que se afasta de suas percepções com o mundo, e, por outro lado, the atribuem papeis de gênero criadores de dependência" (TOLDY, 2016, p. 135).

Esse era o caso da teoria de Sigmund Freud (1856-1939) do desenvolvimento psicossexual, que foi elaborada em torno das experiências da criança masculina que culminam no complexo de Édipo. Nessa pesquisa ele defende que:

[...] o superego das mulheres [...] estava prejudicado, pois ele era jamais 'tão inexorável, tão impessoal, tão independente de suas origens emocionais como o exigimos que seja nos homens'. Dessa observação da diferença de que 'para as mulheres o nivel do que é eticamente normal é diferente do que é nos homens'. Freud conclui que as mulheres 'mostram menos senso de justiça que os homens, que elas são menos prontas a sujeitar-se às grandes exigências da vida, que elas são mais frequentemente influenciadas em seus julgamentos por sentimentos de afeição ou hostilidade' (1925, p. 257-258) (GILLIGAN, 1982, p. 16-17).

Outro caso similar são os estudos sobre o desenvolvimento do raciocínio moral em mulheres realizados por Lawrence Kohlberg (1927-1987), aos quais se dirigem boa parte das críticas de Gilligan. Esse psicólogo estabeleceu seis estágios daquele desenvolvimento distribuidos em três níveis diferentes e os atribuiu aos sujeitos participantes no seu estudo, chegando à conclusão de que eles se mostraram válidos e universais, apesar de não ter incluido mulheres nas suas amostras. O primeiro nivel (pré-convencional) seria aquele em que os sujeitos obedecem a normas morais e expectativas sociais que permanecem exteriores ao "eu", seja por medo de uma sanção externa (multa, prisão; expulsão do grupo) (primeiro estágio), seja para satisfazer seus desejos e interesses meramente particulares (segundo estágio). Já no segundo nível (convencional) os sujeitos obedecem a normas morais porque internalizaram uma moral, se conformando às suas normas e buscando corresponder às expectativas sociais que os outros possuem sobre ele, portanto, sob pena de sofrer uma sanção interna (sentimento de vergonha, culpa), seja centrando-se também no ponto de vista de uma terceira pessoal relacional e afetiva, tentando "pôr-se no lugar do outro", isto é, imaginar como ele gostaria de ser tratado (terceiro estágio), seja centrando-se em manter a lei, as normas e os códigos socialmente aceitos, como forma de manter um sistema social e os deveres institucionalizados (quarto estágio). Somente o último nível (pós-convencional) seria considerado mais "adulto", porque nele o raciocínio e o agir moral são autoescolhidos, ou melhor, baseados em principios éticos universais independentemente do contexto e de quem esteja envolvido, de tal modo que aí os sujeitos são capazes de, por exemplo, transgredir uma norma moral, se ela for contrária a um princípio ético, ao bem comum, ao maior bem para o maior número de pessoas (quinto estágio), ou se eles compreenderem a relatividade das normas em função dos princípios éticos por meio de uma consciência principiada (sexto estágio) (TOLDY, 2016, p. 137).

Para Gilligan, se associarmos o desvio de Kohlberg, da exclusão das mulheres de sua pesquisa, ao fato de tradicionalmente, como nos estudos de Freud, as mulheres serem consideradas dependentes afetivamente ou vocacionadas para cuidar dos outros, orientando as suas decisões pelas relações com os envolvidos e pelos laços do cuidado, parece que elas não passarão do terceiro estágio de uma sequência de seis e serão consideradas, portanto, deficientes no desenvolvimento moral. Contudo, as investigações realizadas por Gilligan a levou "a afirmar que não é pelo fato de as mulheres terem em conta os envolvidos que o seu raciocínio é infantil. Aliás, é a partir dessa noção de interação que elas articulam o seu próprio pensar ético" (TOLDY, 2016, p. 138) e são capazes de levar em consideração o contexto, constituido pela interação de múltiplos aspectos, interesses e problemas; e não apenas seus interesses particulares ou do grupo ao qual pertence, implicados na moral vigente na sociedade a qual pertencem, ou mesmo a orientação de uma única proposta de ética, 
sob o argumento já contestado aqui de que haja escolhas autônomas neutras/imparciais sustentadas por um fundamento absoluto.

Na realidade, seria absurdo defender que tentar compreender a situação do outro, resistindo a juizos, considerados objetivos, imparciais e distantes, do que seja bom ou mau, bem como recusar-se a tomar decisões inexoráveis e independentes do contexto e de quem esteja envolvido, por se preocupar com os outros, não tenha relação com decisões autônomas por principios éticos, estando disposto a transgredir uma norma, se ela for contrária a esses princípios (FERREIRA, 2009, p. 48). O que a pesquisa de Gilligan mostrou é que levar em consideração a situação do outro e o contexto não significa não avaliar decisões morais com base em conceitos morais, como pensou Kohlberg, mas em "ver coisas" que os demais "não veem", tornando-se capaz de tomar decisões com maior dificuldade, mas também de maneira mais justa, o que se pôde concluir a partir das falas das mulheres que naquela época fizeram parte de seus estudos. Gilligan observou que o raciocinio dos homens se concentrava em uma noção de justiça (lei vs. vida), como se se tratasse de um concurso de direitos, enquanto o das mulheres se concentrava na ideia de cuidado (decisão vs. impacto da decisão), como se o que estivesse em jogo fosse uma teia de relações de cuja continuação dependem todos/as (TOLDY, 2016, p. 139).

Uma ética baseada no tipo de condição observada em homens é similar ao modelo kantiano que anunciei anteriormente, segundo o qual uma espécie de acordo, em torno dos valores morais que nos permitem saber e esperar que os outros reconheçam, constitui a coisa certa a fazer, enquanto uma ética baseada no tipo de condição observada em mulheres configuraria uma ética do cuidado, segundo a qual tentar compreender a situação pela qual o outro está passando e buscar encontrar uma maneira de manter uma teia de relações em que todos/as possam desenvolver sua humanidade, deve ser o objetivo principal. Gilligan concluiu que ante os conflitos vividos por mulheres, ao terem que desempenhar papeis que
Ihes são atribuidos e viver situações indesejadas que foram causadas principalmente por outros, elas reinventaram "uma nova experiência de ligação, uma forma de ser com os outros que the permite ser também consigo própria" (GILLIGAN, 1982 apud TOLDY, 2016, p. 139-140).

Entendido desse modo, a questão do cuidar passa da busca por corresponder ao esperado socialmente, muitas vezes, com o sacrificio de escolhas próprias, a uma escolha responsável que não destrói a possibilidade de autoafirmação e levaria todos os envolvidos igualmente em consideração, como sujeitos de direitos, mas também de deveres. Nas palavras de Gilligan:

A responsabilidade pelo cuidar [,uma
responsabilidade de todos/as,] inclui
tanto o eu como o outrol, encarado
como diferente e ligado, e não separado
e oposto,] e a determinação em não
magoar, liberta de constrangimentos
convencionais, sustenta o ideal do cui-
dado, ao mesmo tempo que se [centra]
na realidade da escolha (GILLIGAN, 1982
apud TOLDY, 2016, p. 141).

Uma ética do cuidado propõe, portanto, do ponto de vista do conteúdo, uma ampliação das éticas antigas, uma vez que leva em consideração não apenas direitos, mas também o contexto e, com ele, as relações humanas em toda sua complexidade, contribuindo para a solução de problemas morais urgentes, sem excluir ou mesmo eliminar determinadas maneiras de ser e viver. Além disso, tal concepção de ética termina propondo, do ponto de vista formal, uma correção das fundamentações absolutas da moral, uma vez que se justifica por ser capaz de incluir uma práxis humana determinada, sem precisar sustentar o mito da existência de um fundamento absoluto e, ao mesmo tempo, sem abdicar da pretensão de valer universalmente para todos/as.

\section{Considerações finais}

Com a ideia de que as relações afetivas não têm de significar dependência, dissociando o mito da imparcialidade da ideia de autonomia, e de que uma ética do cuidado eliminaria a suposta necessidade de hierarquias de dominação, que 
têm como consequência aquela solução rápida indicada no começo do texto e, com ela, sujeição, violência ou distribuição desigual do poder etc., Gilligan chegará a uma nova compreensão ética com potencialidades universais, o que contraria a segunda crítica que normalmente se faz a uma ética feminista, que ela careceria de originalidade. Ouvir uma voz relacional significa igualmente uma forma de articular psicologia e filosofia, moral e política, cuidado e justiça, universal e particular.

Em outros termos, ela consegue enfrentar, simultaneamente, três problemas centrais das teorias contemporâneas e do campo da moralidade: o problema da falha dupla, isto é, a falha ocasionada pela exclusão das mulheres como objetos e como sujeitos de pesquisa, e a falha do enfoque androcêntrico; o problema da ilusão/ficção das esferas separadas, isto é, que separa moral e política, público e privado, abstrato e concreto, universal e particular; e o problema do sistema de privilégios e dominação com base no gênero, que é

[...] responsável pela organização de diferenças humanas de forma hierarquizada, possibilitando a distribuição desigual de poder entre os participantes de uma determinada sociedade, e que interage com uma série de marcadores sociais, como raça/etnia, classe, nível de escolaridade, idade, religião, orientação sexual, condição física e mental etc. (ZIRBEL, [2018])

Com isso se mostra que uma ética filosófica pode receber esse adjetivo de "feminista", não por ter origem em uma visão tendenciosa, que quer elevar as práticas de algumas mulheres ao estatuto de uma moral, o que seria incorrer em algo que rejeitamos como empirismo moral, mas por modificar a moral ao considerar outras condições da existência humana, outras verdades sobre a vida, que foram omitidas por organizações sociais, como o patriarcado, e expostas pelo feminismo. É por isso que seus conteúdos e questões não estariam contemplados pelas éticas antigas. Por outro lado, muitas propostas hostis a uma ética, como à ética do cuidado, muitas vezes buscam fundar a moral em ideias e conceitos, que acobertam certas preferências e interesses baseados também no gênero.
Ao longo da história, o feminismo (a luta em prol da plena realização das mulheres; por igualdade de gêneros) se manteve como necessário, e apesar de os papeis que as mulheres desempenham na sociedade e sua situação terem mudado, ainda não está ao alcance de todas elas escolher entre oportunidades do mesmo modo que os homens. Pensamos que seria muito bom se não precisássemos mais insistir em palavras como "ética", "feminismo", mas conseguir realizar nossas tarefas humanas, e se essas palavras se fazem ainda tão atuais e presentes é porque são urgentes. Tendo consciência disso, talvez possamos aceitar a vida como árdua, difícil, uma luta perpétua, não apenas por uma condição de nossa existência, mas também porque o pensamento de que outras pessoas são inferiores é sempre uma possibilidade à espreita para todos/as nós, e por mais que possamos muitas vezes falhar em nossas tentativas de viver a ficção de que a vida possa ser melhor, precisamos lutar contra aquele pensamento, que está nas raízes da violência, da violação, da opressão, em uma palavra, da barbárie.

\section{Referências}

BADINTER, Elisabeth. O conflito: a mulher e a mãe. Trad. Véra Lucia dos Reis. Rio de Janeiro: Record, 2011.

BEAUVOIR, Simone de. O segundo sexo: fatos e mitos / A experiência vivida. Trad. Sérgio Milliet. 3. ed. Rio de Janeiro: Nova Fronteira, 2016.

BíBLIA. Novo Testamento: Apóstolos, Epístolas, Apocalipse. Trad. do grego Frederico Lourenço. São Paulo: Companhia das Letras, 2018.

CORTINA, Adela. Ética. Trad. Silvana Cobucci Leite. 6. ed. São Paulo: Edições Loyola, 2015.

DONATH, Orna. Mães arrependidas: uma outra visão da maternidade. Trad. Marina Vargas. Rio de Janeiro: Civilização Brasileira, 2017.

FERREIRA, Maria Luísa Ribeiro. As mulheres na filosofia. Lisboa: Edições Colibri, 2009.

FRONTEIRAS DO PENSAMENTO. Martha Nussbaum - Entrevista Exclusiva. Youtube. 2018. Disponivel em https://www.youtube.com/watch?v=e3ssHUZIUfs\&$\mathrm{t}=3 \mathrm{~s}$. Acesso em 26/08/2019.

GADAMER, Hans-Georg. Über die politische Inkompetenz der Philosophie. In: Hermeneutische Entwürfe: Vorträge und Aufsätze. Tübingen: Mohr Siebeck, 2000. 
GILLIGAN, Carol. Uma voz diferente: psicologia da diferença entre homens e mulheres da infância à fase adulta. Trad. Nathanael C. Caixeiro. São Paulo: Rosa dos Tempos, 1982.

KANT, Immanuel. A paz perpétua e outros opúsculos. Trad. Artur Morão. Lisboa: Edições 70, 2016.

KANT, Immanuel. Crítica da Razão Prática. Trad. Valério Rohden. São Paulo: Martins Fontes, 2002.

KANT, Immanuel. Fundamentação da metafísica dos costumes. Trad. Paulo Quintela. 3. ed. Lisboa: Edições 70, 2011.

LOPARIC, Zeljko. O fato da razão - uma interpretação semântica. Analytica, Campinas, v. 4, n. 1, p. 13-52, 1999.

LOPARIC, Zeljko. As duas metafísicas de Kant. Kant e-Prints, Campinas, v. 2, n. 5. p. 1-10, 2003.

NUSSBAUM, Martha. Sem fins lucrativos: por que a democracia precisa das humanidades. Trad. Fernando Santos. São Paulo: Editora Martins Fontes, 2015.

ROCHA, Ronai Pires da. De um ponto de vista etnológico. In: DALL'AGNOL, Darlei (org.). Verdade e respeito: a filosofia de Ernst Tugendhat. Florianópolis: Ed. UFSC, 2007.

ROUSSEAU, Jean-Jacques. Emilio ou Da educação. Trad. Roberto Leal Ferreira. 3. ed. São Paulo: Editora Martins Fontes, 2004

ROVERE, Maxime (org.). Arqueofeminismo: Mulheres filósofas e filósofos feministas - séculos XVII-XVIII. Trad. Andrea Maria Mello, Camila Lima de Oliveira, Pedro Muniz, Viviana Ribeiro, Yasmin Haddad. São Paulo: n-1 edições, 2019

SAFATLE, Vladimir. O dever e seus impasses. São Paulo: Martins Fontes, 2013

TOLDY, Teresa. Carol Gilligan. In: FERREIRA, Maria Luísa Ribeiro; HENRIQUES, Fernanda (Coord.). Marginalidade e alternativa. Lisboa: Edições Colibri, 2016.

TUGENDHAT, Ernst. Lições sobre ética. Trad. Grupo de doutorandos do curso de pós-graduação em Filosofia da Universidade do Rio Grande do Sul. 9. ed. Petrópolis: Vozes, 2012.

TUGENDHAT, Ernst. O problema da moral. Porto Alegre: EDIPUCRS, 2003

WOOLF, Virginia. Um teto todo seu. Trad. Bia Nunes de Sousa, Glauco Mattoso. São Paulo: Tordesilhas, 2014.

WOLLSTONECRAFT, Mary. Reivindicação dos direitos da mulher. Trad. Ivania Pocinho Motta. São Paulo: Boitempo, 2016

ZIRBEL, Ilze. Duas objeções a uma filosofia feminista. ANPOF. 2018. Disponivel em http://anpof.org/portal/index.php/pt-BR/agenda-encontro-2018/item/ 559-categoriaagenda2018/18710-duas-objecoes-a-uma-filosofia-feminista. Acesso em 26/08/2019.

\section{Viviane Magalhães Pereira}

Doutora em Filosofia pela Pontificia Universidade Católica do Rio Grande do Sul (PUCRS, Porto Alegre, RS, Brasil), professora da Universidade Estadual do Ceará (UECE), Fortaleza, CE, Brasil

\section{Endereço para correspondência}

Viviane Magalhães Pereira

Universidade Estadual do Ceará

Av. Luciano Carneiro, 345, Centro de Humanidades, sala 106

Fátima, 60411-205

Fortaleza, CE, Brasil 